\title{
Is there a positive association between mammographic density and bone mineral density? Authors' response
} Carolyn Crandall ${ }^{1}$, Shana Palla ${ }^{2}$, Beth A Reboussin², Giske Ursin ${ }^{3,4}$ and Gail Greendale ${ }^{5}$

\author{
1Division of General Internal Medicine, David Geffen School of Medicine at University of California, Los Angeles, CA, USA \\ 2Department of Public Health Sciences, Wake Forest University School of Medicine, Winston-Salem, NC, USA \\ ${ }^{3}$ Department of Preventive Medicine, USC Norris Comprehensive Cancer Center, Los Angeles, CA, USA \\ ${ }^{4}$ Department of Nutrition, University of Oslo, Oslo, Norway \\ ${ }^{5}$ Department of Geriatrics, David Geffen School of Medicine at University of California, Los Angeles, CA, USA
}

Corresponding author: Carolyn Crandall, ccrandall@mednet.ucla.edu

Published: 1 May 2006

Breast Cancer Research 2006, 8:404 (doi:10.1186/bcr1393)

This article is online at: http://breast-cancer-research.com/content/8/2/404

(c) 2006 BioMed Central Ltd

See related research article by Crandall et al. in issue $7.6 \mathrm{http} / / /$ breast-cancer-research.com/content/7/6/R922 and related letter by Dite et al. in issue $8.1 \mathrm{http}: / /$ breast-cancer-research.com/content/8/1/401

We read with interest the issues raised by Dite and coworkers [1] in their response to our recent research article [2], and we are pleased to address them. In their letter, Dite and colleagues present previously unpublished results that reveal no association between bone mineral density and mammographic density in female twins. Relevant information about the characteristics of the study participants, the methods of measuring mammographic density, and the timing of the mammograms in relation to the bone density assessment are not supplied. Differences in study samples, methods, and sample size could account for the difference between their results and ours.

Dite and coworkers [1] posit several explanations for the apparent discrepancy between their study and ours. First, they suggest that our results were an artefact of our performance of multiple analyses. In fact, we performed only three regression analyses, and these analyses were based on clearly stipulated a priori hypotheses. We believe that a strict Bonferroni adjustment for multiple testing would have been overly conservative.

Second, they argue that we might have been misled by outliers or influential points. However, we performed outlier analyses using the dfBeta approach [3], which confirmed that our results were not unduly influenced by extreme data points. It is impossible to rule out chance as a possible explanation for our results, but with a few exceptions this criticism applies to all studies.

Finally, Dite and colleagues state that we might have assumed effect modification without testing for it. We tested for effect modification between recent use of hormone therapy and lumbar bone mineral density by adding an interaction term to the linear regression model that included age, body mass index, smoking, lumbar bone mineral density, and recent hormone therapy as covariates, and mammographic density as the outcome. The $P$ value for the lumbar bone mineral density-recent hormone therapy interaction term was 0.0583 at the lumbar spine. Similar results were apparent at the hip $(P=0.094$ for the interaction term). On this basis, we conclude that recent hormone therapy modifies the association between bone mineral density and mammographic density. We stand by our results and hope to elucidate what biologic factors may be responsible for the association between mammographic density and bone mineral density in our study.

\section{Competing interests}

The authors declare that they have no competing interests.

\section{References}

1. Dite GS, Wark JD, Giles GG, English DR, McCredie MRE, Hopper $\mathrm{JL}$ : Is there a positive association between mammo-graphic density and bone mineral density? [letter]. Breast Cancer Res 2006, 8:401.

2. Crandall C, Palla S, Reboussin BA, Ursin G, Greendale GA: Positive association between mammographic breast density and bone mineral density in the Postmenopausal Estrogen/Progestin Interventions Study. Breast Cancer Res 2005, 7:R922-R928.

3. Myers RH: Classical and Modern Regression with Applications Boston: Duxbury Press; 1986:284-288. 